\title{
$\mathfrak{3} \mathfrak{n} \mathfrak{g} \mathbf{l t}$.
}

Gittleitung. Seite

1. Entftehung bes Straigejebbudis ......... 1

2. Gejdidite ber Strafredtäreform . . . . . . . 2

\section{Strafgejesbu仿 ntit Cinführungâgefes.}

Ginjuhrungêgefen z. St 1870. $\S \S 1-8$

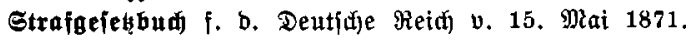
$\S \S 1-370$

Ginleitenbe Bejtimmungen $\$$ 1-12.

\section{Eriter Teil.}

Bon ber Beitrafung ber Berbedien, Bergerjen und fther: tretungen im allgemeinen.

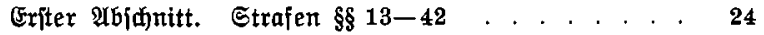

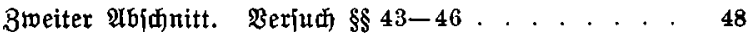

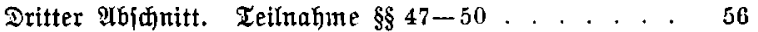

Bierter abjantitt. Gründe, welthe bie Strafe aus= 低ließ̉en ober milbern $\$ \$ 51-72$. . . . . . . . . 70

Fünfter Abjanitt. Bujantmentrefien mehrerer itrał* barer \$anblungetı $\$ \$ 73-79$. . . . . . . . . . . 100

\section{3weiter Teil.}

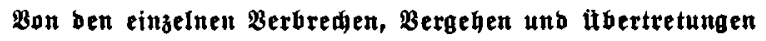
unb beren Beftrafung.

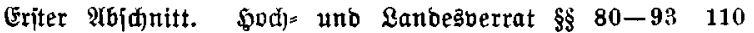
[Die Beitimmungen bez Broiten und Dritten Abidnitts

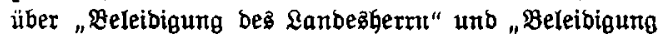
von Sundeşfüriten" jinb jebt gegenjtanbštos.] 


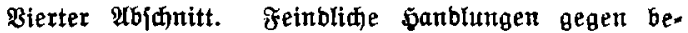
freunbete Staaten $\$ \$ 102-104 \ldots . . . . . . .122$

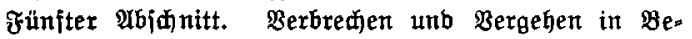

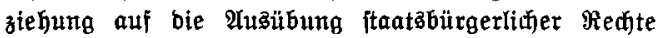
$\$ \$ 105-109 \ldots \ldots \ldots \ldots$

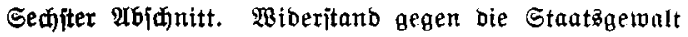

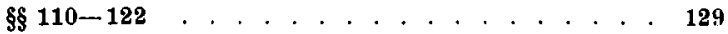

Siebenter $\mathscr{H b}$ finitt. Berbreden utto Bergehen wiber

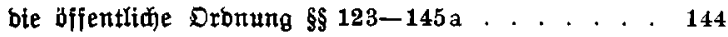

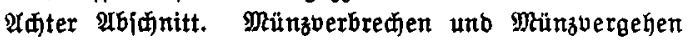

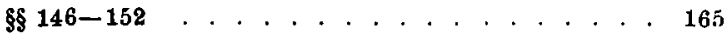

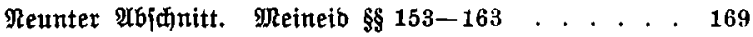

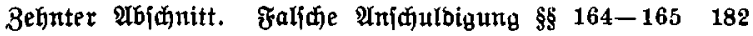

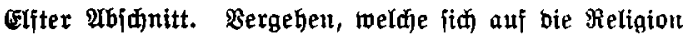
beżiehen $\$ 166-168 \ldots \ldots . \ldots . . . . .185$

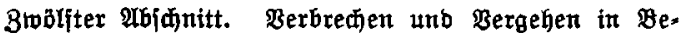

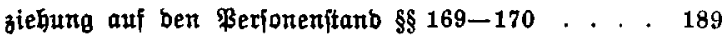

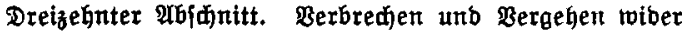

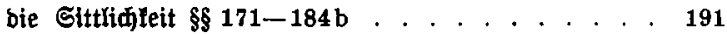

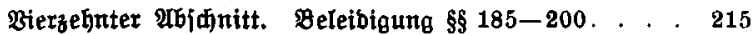

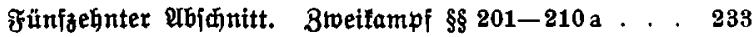

Sedjzegnter 2rbjhitt. Berbredien unb Bergefen wiber

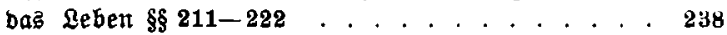

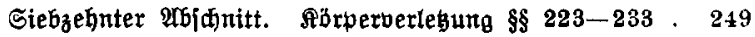

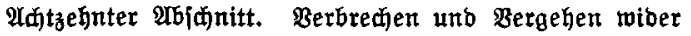

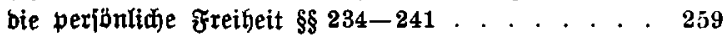

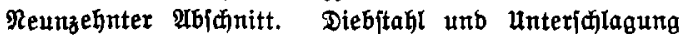
$\$ 242-248 \mathrm{a} \ldots \ldots . . . . . . .266$

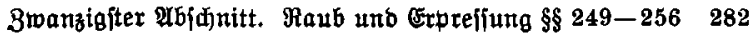

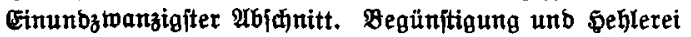
$\$ 257-262$. . . . . . . . . . . . . . . . . . 289

3weiunbz̧wanzigiter abjanitt. Betrug und Untreue

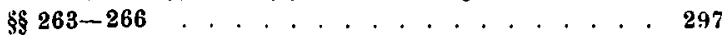

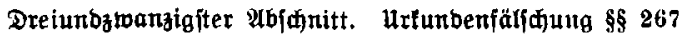
biž $280 \ldots \ldots \ldots \ldots$. . . . . . . . . 312 


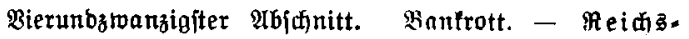
tonfurborbnung $\$ \$ 239-244 \ldots . . . . . .330$

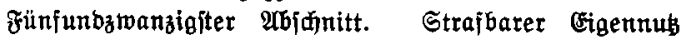
unto Berlebung frember Geheimniffe $\S \S 284-302$ e 338

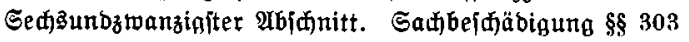
bis 305. . . . . . . . . . . . . . . . . . . . 360

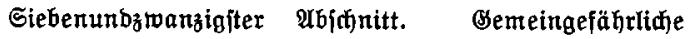
Berbred)en unt Bergehen $\$ 3306-330 \ldots \ldots 3$

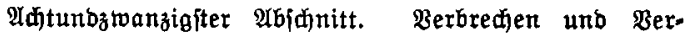
gehen im Amte $\$ 331-359 \ldots \ldots . . \ldots . . . . .382$

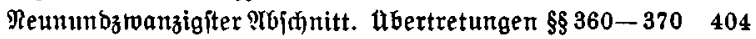

\section{$\mathfrak{A n t h a n g}$}

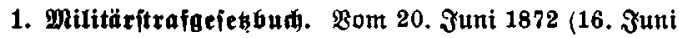
1926) . . . . . . . . . . . . . . . . 428

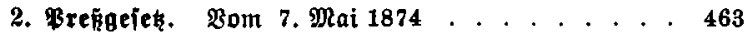

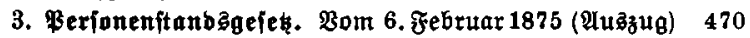

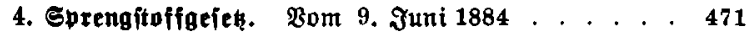

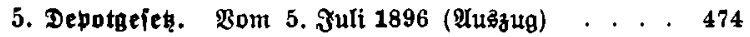

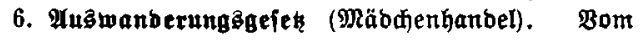

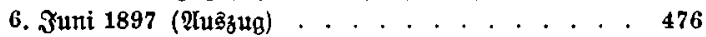

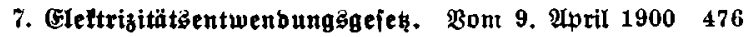

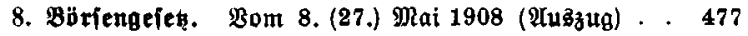

9. Epinnagegeiel. Bom 3. Juni $1914 \ldots \ldots$. . . 479

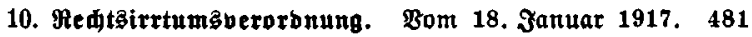

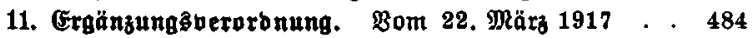

12. Reiđjăbgabenwrbnang. Bom 13. Dezember 1919.

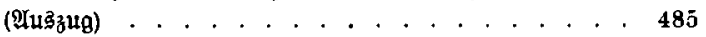

13. Straftilgungageík. Bam 9. April 1920 . . . . . 494

14. Berorbnung betr. Stillegund Iebensmidtiger Be. tritbe. Bom 10. November $1920 \ldots \ldots$. . . 497

15. Mennwett* unb Rotteriegeiew. Bom 8. Ipril 1922

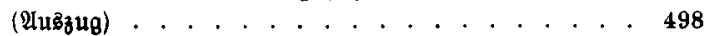

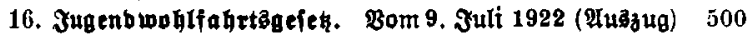


17.

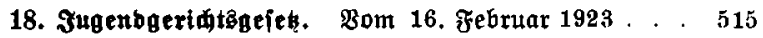

19. Potgefet. Bom 24. Februat 1923 (\{uszug) . . . 527

20. Etrafodizugêgrunbiäłe. Bom 7. Juni 1923 . . . 528

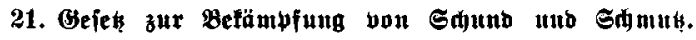
Bom 18. Dezember 1926 . . . . . . . . . . . . . 567

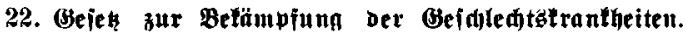
Bom 18, Februar 1927 . . . . . . . . . . . . . . 571

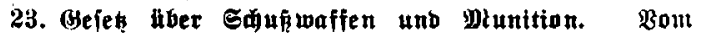
12. April 1928 . . . . . . . . . . . . . . . . . 577

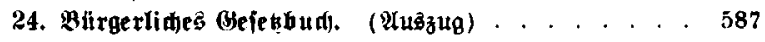

Sadregifter . . . . . . . . . . . . . . . . . . . . *1

\section{כu Zext abgebruitte Geję̧e und Beroromungen}

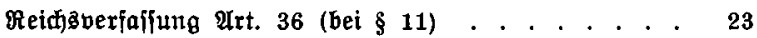

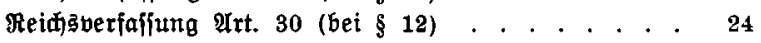

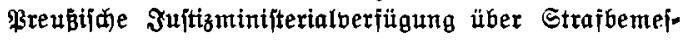

\{ung vom 8. März 1926 (vor $\S 13$ ) . . . . . . 26

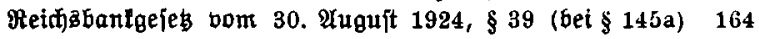

Bejes über ben Berfehr mit uneblen Metallen vou

23. $3 u l i$ 1926, $\$ 17$ (bei $\S 243$ ) . . . . . . . . 270

Befeg über ben Berfehr mit (Ebelmetallen vom 29. Junt 1926, §4 (bei $\S 243$ ) . . . . . . . . . . . . 271

Ganbelşgefebbuch bom 10: Mai 1897, $\$ 312$ (bei $\S 266$ ) 304

\$npothefenbanfgeies bom 13. 3uli 1899, §36 (bei $\$ 266$ ) 304

Aontursorbnung vom 17. Mai 1898, \$\$ 239-244 (itatt

$\$ \$ 281-283$ ) . . . . . . . . . . . . . . . . 331 